\title{
Ferrite content measurement in super duplex stainless steel welds
}

\author{
Vahid A Hosseini ${ }^{1,2}$ (D) $\cdot$ Kjell Hurtig $^{1} \cdot$ Daniel Eyzop $^{3} \cdot$ Agneta Östberg $^{4} \cdot$ Paul Janiak $^{5} \cdot$ Leif Karlsson $^{1}$ \\ Received: 24 September 2018 / Accepted: 20 November 2018 / Published online: 5 December 2018 \\ (C) The Author(s) 2018
}

\begin{abstract}
Approaches to determining ferrite fraction (\%) and ferrite number (FN) were examined for super duplex stainless steel (SDSS) welds. A reference sample was produced by bead-on-plate gas-tungsten arc welding of a type-2507 SDSS plate. By comparing different etchants and measurement practices, it was realized that etching with modified Beraha followed by computerized image analysis (IA) was the most accurate and quickest technique to measure ferrite fraction, which determined the same ferrite fraction $(68.0 \pm 2.6 \%)$ as that measured by electron diffraction backscattered analysis $(67.6 \pm 2.3 \%)$. A Round Robin test was performed on a reference sample at University West, Swerea KIMAB, Outokumpu Stainless, and Sandvik Materials Technology to investigate the repeatability of the technique. The ferrite fraction measurements performed at different laboratories showed very small variations, which were in the range of those seen when changing microscope in the same laboratory. After verification of the technique, the relationship between ferrite fraction and ferrite number (measured with FERITSCOPE®) was determined using 14 single (root) pass welds, including butt, corner, and T-, V-, and double V-joint geometries. The best-fit equation found in this study was ferrite number $(\mathrm{FN})=1.1 \times$ ferrite fraction $(\%)$. To conclude, the ferrite fraction technique suggested in the present paper was accurate and repeatable, which made it possible to determine a ferrite fraction-ferrite number formula for SDSS singlepass welds.
\end{abstract}

Keywords Ferrite fraction $\cdot$ Ferrite number $\cdot$ Image analysis $\cdot$ Round Robin $\cdot$ Super duplex stainless steel $\cdot$ Point counting

\section{Introduction}

Duplex stainless steels (DSS), with a microstructure consisting of balanced ferrite and austenite fractions, have been used in many applications thanks to their excellent combination of good mechanical properties and high corrosion resistance. These steels are suitable alternatives for austenitic stainless

Recommended for publication by Commission IX - Behaviour of Metals Subjected to Welding

Vahid A Hosseini

vahid.hosseini@hv.se

1 Department of Engineering Science, University West, SE-46186 Trollhättan, Sweden

2 Innovatum AB, Trollhättan, SE-461 29 Trollhättan, Sweden

3 Outokumpu Stainless AB, Avesta Research Centre, Box 74, SE-77422 Avesta, Sweden

4 Sandvik Materials Technology, SE-811 81 Sandviken, Sweden

5 Swerea KIMAB AB, Box 7047, SE-164 07 Kista, Sweden steels, particularly where the risk for stress corrosion cracking is prominent $[1,2]$. Flat and tubular forms are major DSS products, which are mostly joined by arc welding processes. Welding thermal cycles, however, can adversely affect the performance of DSS, as different metallurgical phenomena may degrade their unique microstructure and properties [3-6].

Ferrite fraction is an important microstructural variable influencing mechanical properties and corrosion resistance of duplex stainless steels [1]. It has been claimed that duplex microstructures with an equal fraction of ferrite and austenite offer the optimum combination of corrosion resistance and mechanical properties. High ferrite fractions decrease toughness and elongation whereas low ferrite fractions increase the susceptibility to chloride stress corrosion cracking [7].

Different standards, therefore, have introduced criteria for the allowable ferrite fraction in base metal, heat affected zone, and weld metal of DSS welds. For instance, API technical report 938-C [8] requires the ferrite fractions of 30-65\% for base metal, 40-65\% for HAZ, and 25-60\% for weld zone. NACE MR0175 [9] states that the ferrite fraction shall be between 35 and $65 \%$ for wrought and cast structures and 30 and $70 \%$ for weld zone root and un-reheated weld cap. 
However, Kotecki et al. [10] presented an IIW document reporting that the minimum ferrite fraction limit could be modified for 2205 DSS, as the welds with low ferrite fractions still showed acceptable stress corrosion cracking and strength. In a recent project [11], the steps toward developing a database for a software predicting microstructure of duplex stainless steels welds were introduced and it was mentioned that the most important output of the software is ferrite content (fraction and number). Due to the critical importance of ferrite content for the properties, different direct and indirect approaches have been proposed to measure ferrite fraction and number [12-15].

In the direct approaches, the ferrite fraction is measured using optical microscopy-based techniques such as point counting (PC) and image analysis (IA) [15-17] and scanning electron microscopy-based techniques such as electronbackscattered diffraction (EBSD). PC is a time-consuming technique but is manual and applicable without an image analyzing program. IA, on the other hand, is a quicker method but demands more skilled technicians and computer-based software packages. A proper etching technique is the first step toward the measurement of the ferrite fraction using optical microscopy techniques. Electrolytic etching using $\mathrm{NaOH}, \mathrm{KOH}$, and oxalic acid as well as color etching using Beraha and Murakami has been employed for ferrite measurement and detecting intermetallics [18]. However, obtaining a proper contrast between ferrite and austenite is sometimes problematic in the weld zone [5]. Although the EBSD phase fraction measurement technique is expensive and time-consuming, it provides the most accurate and reliable results, which are normally used as a reference to verify other measurement techniques [16].

Indirect approaches such as magnetic measurement using FERITSCOPE®, X-ray diffraction, and prediction based on chemical composition using the WRC-92 diagram, ThermoCalc, and JMatPro have also been utilized to determine the ferrite content in DSS. The magnetic measurement using FERITSCOPE® is more practical, as it can rapidly provide reliable results, and different research papers, standards, and IIW documents developed a methodology to measure the ferrite fraction using this technique [14, 19]. However, the risk of a large scatter in results (up to $20 \%$ in real weld metal) and the need for calibration are drawbacks [12].

The correlation between the ferrite number and percentage is another important subject in DSS research [20]. Kotecki [14] showed that the ferrite number of a $100 \%$ ferritic microstructure is reduced with decreasing iron content of the alloy, which implies that the ferrite number is specific for each alloy. In addition, the final surface quality can affect the ferrite number up to $12 \%$ [12], which makes the correlation of ferrite number and ferrite fraction more complicated particularly for welds.

The evolution of ferrite fraction in the multipass welded samples has generated considerable research interest in DSS, as the trend toward the application of thicker components has been increasing [21]. In a recent IIW document, Putz et al. [22] studied the ferrite fraction at different locations in 2205 DSS welds and showed that the standard deviation for the ferrite fraction was around $12 \%$ in a reheated bead of a multipass weld. Therefore, the local ferrite fraction can significantly vary in each bead, which could alter the properties locally.

Ferrite content measurement in super duplex stainless steels, containing high contents of $\mathrm{Cr}$ and $\mathrm{Ni}$, has not been systematically addressed until now. For instance, the ferrite fraction measurement still lacks a Round Robin test for the assessment of etching as well as IA and PC. In addition, the relationship between ferrite fraction and ferrite number is still unknown for SDSS welds. The present study systematically investigates the ferrite measurements with metallography and EBSD techniques, the Round Robin test in different laboratories and in one laboratory also with different microscopes, and the ferrite number-ferrite fraction relationship in SDSS welds. This paper is therefore aimed at providing a guideline for the ferrite determination in SDSS welds.

\section{Experimental}

In this section, the materials used for welding experiments are introduced. Then, experimental approaches toward the development of a ferrite fraction determination technique and the determination of ferrite fraction-ferrite number relationship in single-pass SDSS welds are explained.

\subsection{Materials}

Type 2507 SDSS plates with different thicknesses were used for welding experiments. The chemical compositions of plates and welding consumables used for the experiment are detailed in Table 1.

\subsection{Development of ferrite fraction determination technique}

The experiment process flow to develop a ferrite fraction determination technique is illustrated in Fig. 1.

A reference sample was produced using bead-on-plate gastungsten arc welding of a 6-mm-thick type 2507 SDSS plate. The sample was sectioned, mounted, ground, and polished down to $0.05-\mu \mathrm{m}$ alumina suspension.

\subsubsection{Comparison of etchants}

For comparison of different etchants, the polished sample was etched using the following reagents: 
Table 1 Chemical composition (wt.\%) of plates and welding consumables

\begin{tabular}{lccccccccccc}
\hline \multicolumn{2}{c}{$\mathrm{C}$} & $\mathrm{Si}$ & $\mathrm{Mn}$ & $\mathrm{P}$ & $\mathrm{S}$ & $\mathrm{Cr}$ & $\mathrm{Ni}$ & $\mathrm{Mo}$ & $\mathrm{N}$ & $\mathrm{Cu}$ & $\mathrm{W}$ \\
\hline \multicolumn{2}{l}{ Base materials } & & & & & & & & & & \\
$3 \mathrm{~mm}$ & 0.016 & 0.4 & 0.7 & 0.024 & 0.001 & 24.1 & 6.9 & 3.8 & 0.29 & 0.20 & - \\
$6 \mathrm{~mm}$ & 0.020 & 0.4 & 0.8 & 0.03 & 0.001 & 25.0 & 6.9 & 3.8 & 0.27 & 0.40 & - \\
$10 \mathrm{~mm}$ & 0.019 & 0.4 & 0.8 & 0.027 & 0.001 & 24.8 & 7.0 & 3.8 & 0.27 & 0.24 & 0.05 \\
$13 \mathrm{~mm}$ & 0.013 & 0.3 & 0.8 & 0.021 & 0.001 & 25.5 & 7.2 & 3.9 & 0.28 & 0.18 & 0.02 \\
$24 \mathrm{~mm}$ & 0.018 & 0.4 & 0.8 & 0.027 & 0.001 & 24.7 & 6.8 & 3.77 & 0.28 & 0.24 & 0.05 \\
Welding consumables & & & & & & & & & & \\
TIG/MIG* & 0.015 & 0.4 & 0.6 & 0.014 & 0.001 & 25.2 & 9.2 & 4.1 & 0.26 & 0.09 & 0.04 \\
SMAW** & 0.024 & 0.5 & 0.9 & 0.017 & 0.003 & 25.3 & 9.3 & 4.3 & 0.21 & - & - \\
SAW* & 0.012 & 0.4 & 0.6 & 0.015 & 0.001 & 24.9 & 9.2 & 3.9 & 0.26 & 0.09 & 0.01 \\
\hline
\end{tabular}

*Wire chemical composition

**All-weld metal chemical composition a. Electrolytic etching using $10 \%$ oxalic acid with $4 \mathrm{~V}$ for $10 \mathrm{~s}$.

b. Electrolytic etching using $7 \%$ oxalic acid with $2 \mathrm{~V}$ and for $10 \mathrm{~s}$ followed by $10 \% \mathrm{KOH}$ etched with $2 \mathrm{~V}$ and $10 \mathrm{~s}$.

c. $20 \% \mathrm{NaOH}$ with $4 \mathrm{~V}$ for $3 \mathrm{~s}$.

d. Color etching using Beraha's reagent with the composition of $60 \mathrm{ml}$ water, $30 \mathrm{ml} \mathrm{HCl}, 0.75 \mathrm{~g}$ potassium bisulfite for 10-12 s. It should be noted that sometimes the potassium bisulfite content was slightly adjusted for the best contrast.

In all experiments, the time between the final polishing step and etching was kept short, less than $10 \mathrm{~s}$, to minimize the oxide formation on the sample.

\subsubsection{Comparison of measurement techniques}

In order to compare different measurement techniques, the ferrite fraction of the weld zone in the reference sample was measured using the following procedure:

a. Point counting, the electrolytically etched sample with $10 \% \mathrm{KOH}$, ASTM E562

b. Point counting, the sample color etched with modified Beraha, ASTM E562 c. Image analysis, sample color etched with modified Beraha

d. EBSD phase measurement on the polished sample

The EBSD measurements were carried out using a Zeiss SIGMA FEG-SEM equipped with a "Nordlys F" EBSD detector supplied by Oxford Instruments. Ferrite fraction was measured with HKL Channel5 software.

All measurements were performed on the centerline of the weld zone.

\subsubsection{Round Robin test}

For the Round Robin test, University West (UW), Swerea KIMAB (SK), Outokumpu Stainless AB (OS), and Sandvik Materials Technology (SMT) participated to measure the ferrite fraction of the reference sample using image analysis. UW, SK, and SMT polished and etched the sample again using modified Beraha, but OS performed the test on the etched sample received from SMT. The intention was to measure the ferrite fraction on the locations indicated in Fig. 2 to make the results comparable. As images obtained with the same magnification in different microscopes covered different areas, it was aimed at taking micrographs covering an area of $280 \mu \mathrm{m} \times 210 \mu \mathrm{m}$ no matter what magnification was selected.

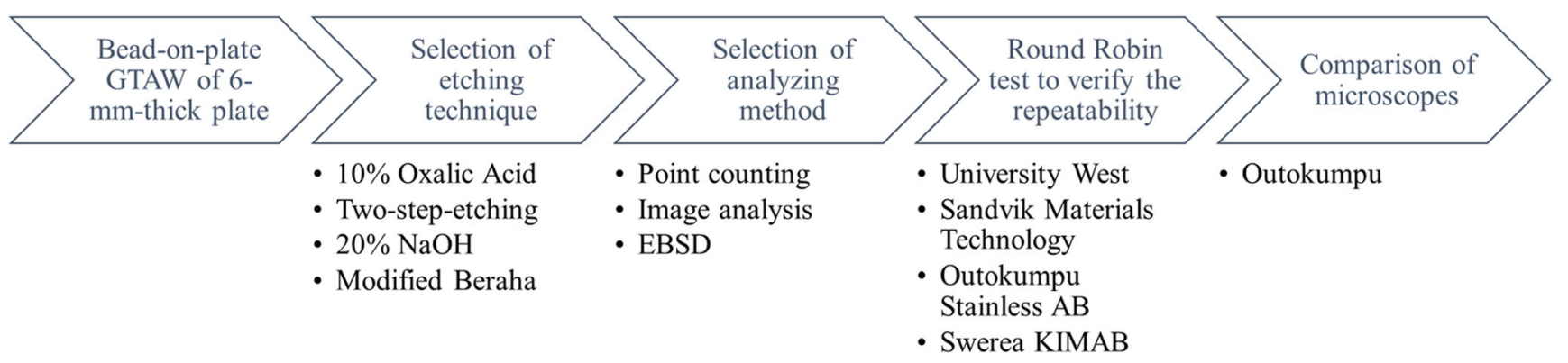

Fig. 1 The experiment process flow for the development of a ferrite fraction determination technique 
Fig. 2 The location of ferrite measurement with IA on the reference sample produced using bead-on-plate GTAW

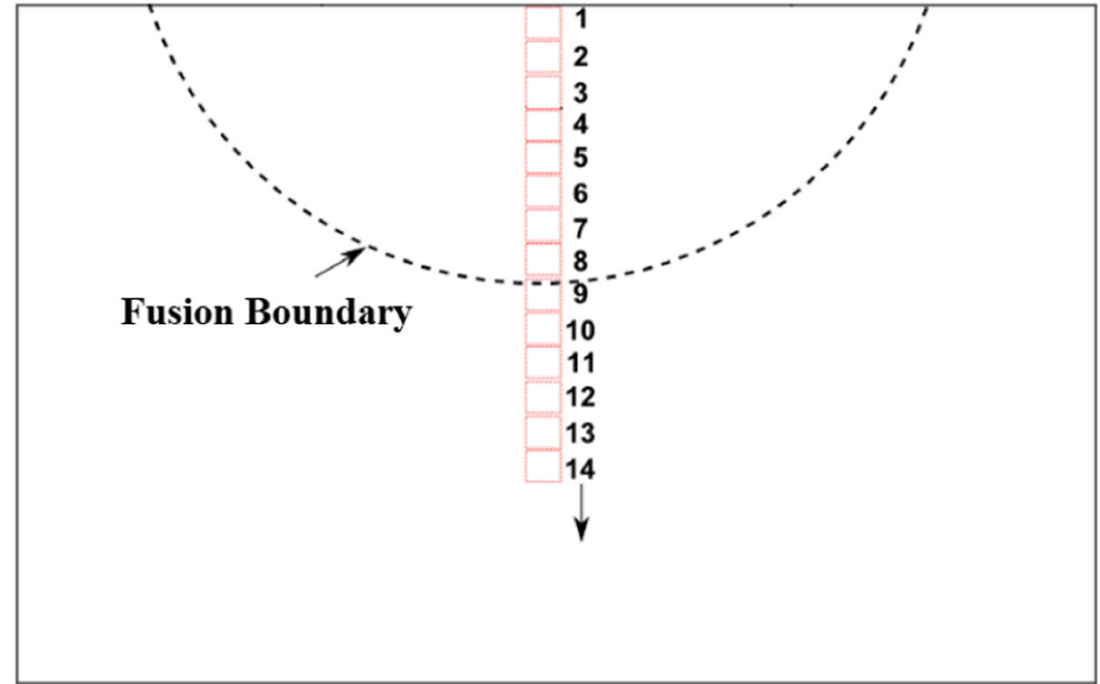

The experiment was performed using an Olympus microscope at UW, a Reichert MEF4M microscope at SMT, a Leica IM DRM at SK, and Zeiss, Optima, and Olympus microscopes at OS.

\subsection{Ferrite fraction and ferrite number in single-pass welds}

After developing the technique to measure the ferrite fraction (etching with the modified Beraha and measuring using the IA approach), 14 welds were produced to relate ferrite fraction to ferrite number in SDSS single-pass welds. Plates were welded using gas-tungsten-arc welding (GTAW), gas-metal arc welding (GMAW), shielded metal arc welding (SMAW), and submerged arc welding (SAW). Different joint geometries, arc energies, and joint preparations were used to vary welding variables. More details about the joint configuration, welding process, and plate thickness are detailed in Table 2. As the aim of this paper is to investigate the ferrite fraction measurement, the details about the welding parameters and its relationship with thermal cycle and microstructure will be presented in another paper.

A metallographic approach similar to that explained for the reference sample followed by etching with modified Beraha was employed to prepare samples from these 14 welds. Ferrite fractions were measured at the top, middle, and bottom of each single-pass welds. The average of ferrite fractions from at least 7 micrographs was calculated for each location. Ferrite number was measured with FERITSCOPE®, MP30, on the surface along the centerline (after slight grinding with $\mathrm{SiC}$ paper-P80 to remove oxides) and cross section of the weld zone and the average of at least 10 measurements was calculated for each sample (Fig. 3). In the instrument manual, it is mentioned that measurements of samples with a thickness below $2 \mathrm{~mm}$ or closer to an edge than $2 \mathrm{~mm}$ must be corrected. The effective volume of measurement can therefore be assumed expected to be a half-sphere with a radius of about $2 \mathrm{~mm}$. The ferrite fractions and ferrite numbers were also measured for the cross section of base metal plates for each thickness.
Table 2 Joint geometry, plate thickness, and welding techniques

\begin{tabular}{|c|c|c|c|c|}
\hline Joint geometry & Thickness & Process & Pass & $\begin{array}{l}\text { Arc energy }(\mathrm{kJ} / \\
\mathrm{mm})\end{array}$ \\
\hline $\mathrm{T}$ joint & $13 \mathrm{~mm}$ & GMAW & $\begin{array}{l}\text { Single } \\
\text { pass }\end{array}$ & $0.88,1.53$ \\
\hline Corner joint & $13 \mathrm{~mm}$ & GMAW, SAW & $\begin{array}{l}\text { Single } \\
\text { pass }\end{array}$ & $0.88,1.53,1.57$ \\
\hline V-grooved* & $3 \mathrm{~mm}$ & GTAW & Root pass & 0.46 \\
\hline Bead on plate V-grooved & $13 \mathrm{~mm}$ & $\begin{array}{l}\text { SAW, GMAW, GTAW, } \\
\text { SMAW }\end{array}$ & Root pass & $\begin{array}{l}0.92,0.91,1.17, \\
\quad 0.65\end{array}$ \\
\hline V-grooved butt & $\begin{array}{l}10 \mathrm{~mm}, \\
21 \mathrm{~mm}\end{array}$ & GTAW, GMAW & Root pass & $1.02,0.94,1.19$ \\
\hline $\begin{array}{l}\text { Double V-grooved butt } \\
\text { weld }\end{array}$ & $25 \mathrm{~mm}$ & GTAW & Root pass & 0.91 \\
\hline
\end{tabular}

*Machined on a plate 


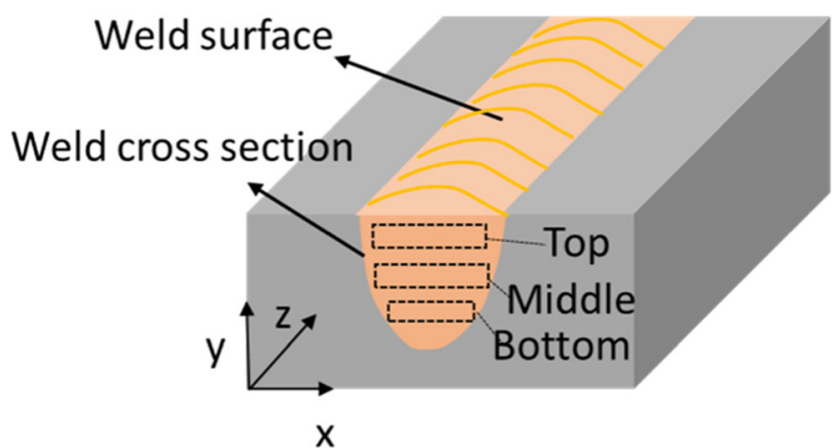

Fig. 3 Schematic illustration of locations for ferrite fraction and ferrite number measurements

\section{Results and discussion}

In the present section, the results of ferrite content measurements are presented and discussed. In the first section, different ferrite fraction techniques were compared on a reference sample to find the best approach suited for SDSS welds. The technique was, then, employed to relate ferrite number and ferrite fraction in single-pass welds. The key findings of the present study are summarized in "Final comments" to be used as guidelines for ferrite content measurement in SDSS welds.

\subsection{Development of ferrite fraction measurement technique}

In this set of experiments, the goal was to find and verify the best practice for ferrite fraction measurement in single-pass welds. The proper etching technique was selected and the ferrite fraction was measured using PC and IA techniques and compared to EBSD as the reference technique. In parallel, the Round Robin test was performed on the reference sample to investigate the scatter of IA results at different partners' laboratory.

\subsubsection{Comparison of different etching techniques}

A cross section of the weld zone in the reference sample especially fabricated for the ferrite fraction measurement study is shown in Fig. 4. To reveal the weld zone, the reference sample was electrolytically etched using $20 \% \mathrm{NaOH}$. The fusion boundary and weld centerline are indicated in the figure. As may be seen, equiaxed grains formed close to the fusion boundary and on the top of the weld zone. However, columnar grains formed in the middle of the weld zone, between the equiaxed grain regions. All microstructural studies were performed on the weld centerline of the reference sample to maintain a consistent location.

The microstructure of the reference sample etched with oxalic acid, two-step etching, $20 \% \mathrm{NaOH}$, and modified Beraha is shown in Fig. 5. The aim was to have the

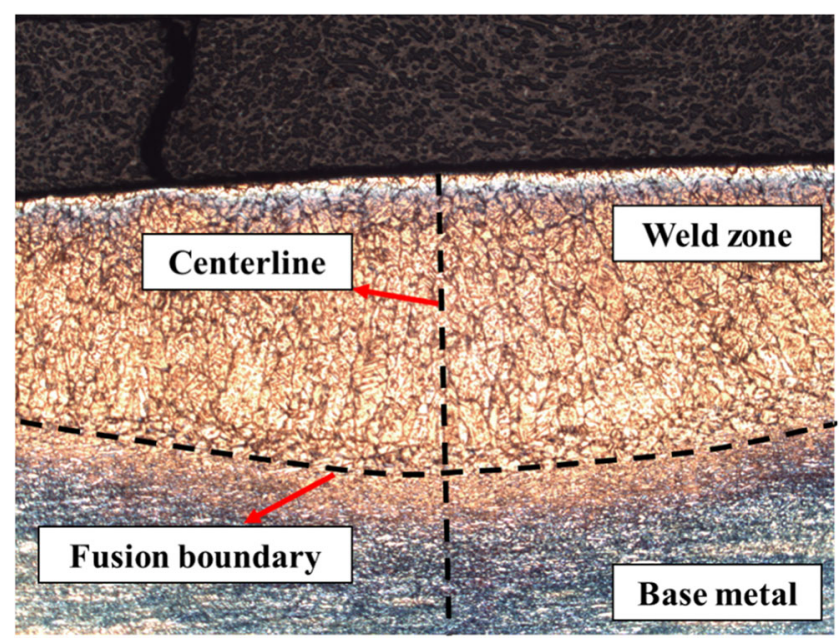

Fig. 4 Cross section of 6-mm-thick sample fabricated by bead-on-plate GTAW for the ferrite fraction measurement experiment (reference sample). The sample was etched using $20 \% \mathrm{NaOH}$

maximum and even phase contrast and clear definition of phase boundaries between ferrite and austenite. This criterion results in micrographs with a proper threshold and quality for PC and IA. If the ferrite and austenite have similar etching response and low contrast, it is not possible for the IA software to separate phases, which causes errors in the measurements.

As shown in Fig. 5a, electrolytically etching with $10 \%$ oxalic acid produced the minimum contrast between ferrite and austenite compared to the other etching procedures. This result was expected as oxalic acid is normally used to find sensitized areas such as locations next to nitrides and intermetallics [23]. Two-step etching did not show a sufficient contrast between ferrite and austenite to be used for the ferrite fraction measurement (Fig. 5b). However, it was successfully used for the measurement of intermetallic fractions in the HAZ of the same sample [6]. As shown in Fig. 5c, the image quality for $20 \% \mathrm{NaOH}$ is much higher than those of oxalic acid and two-step etching. However, the contrast between ferrite and austenite varied significantly from one ferrite grain to another. For example, in the top right corner of Fig. $5 \mathrm{c}$, the ferrite and austenite were etched very different compared to those in the center of the micrograph. It is evident from the micrographs that color etching with modified Beraha provided the best image quality with the highest contrast between ferrite and austenite, where ferrite was etched black and austenite bright.

To further study the etchants, the micrographs were imported to ImagePro software. The only etchant which produced complete phase separation by adjusting the threshold was the modified Beraha.

Etching with modified Beraha, however, needs more care compared to most other etchants, as the sample preparation, chemical composition of etchant, and etching 
Fig. 5 The 6-mm-thick GTAW remelted sample electrolytically etched with a $10 \%$ oxalic acid, b two-step etching, c $20 \% \mathrm{NaOH}$, and $\mathbf{d}$ color etched with modified Beraha. The modified Beraha provided the best contrast between ferrite and austenite
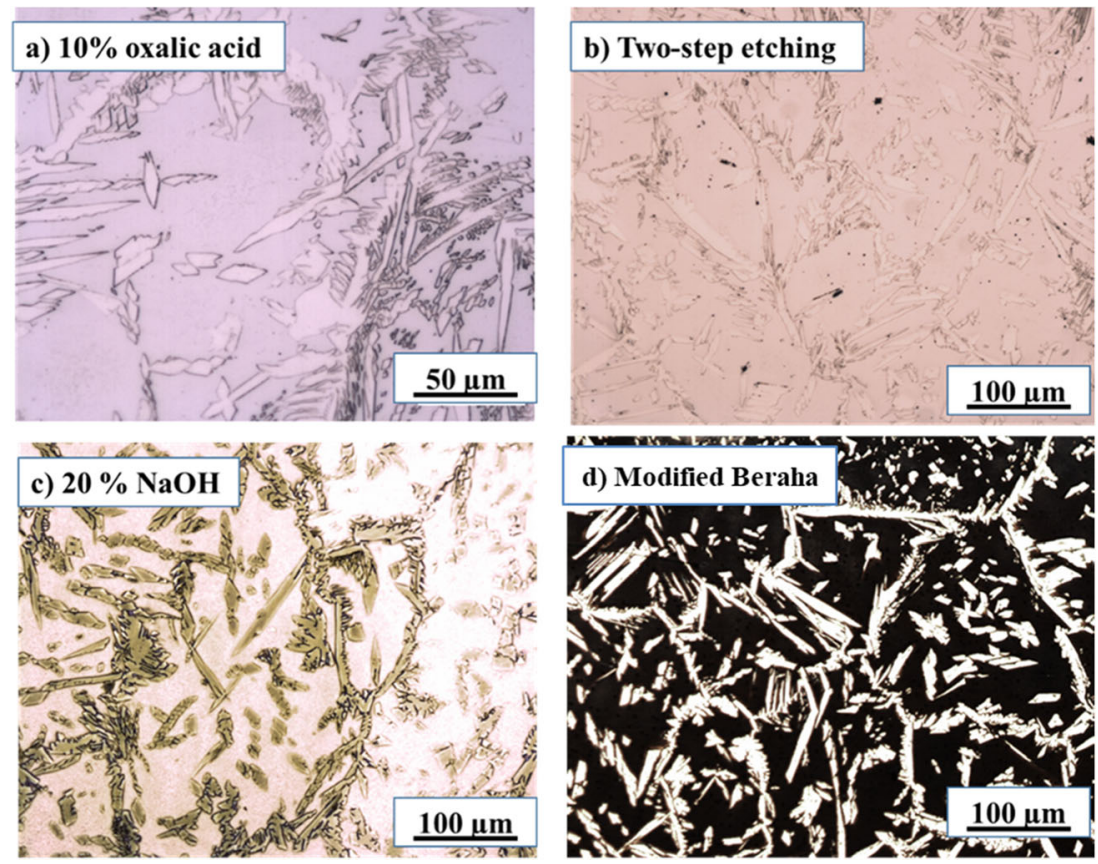

time can markedly influence the quality. The microstructure of two other welds with improper Beraha etching is shown in Fig. 6. A low contrast between fine ferrite located between austenite grains in Fig. 6a can introduce a large error in the measurement of the ferrite fraction. It may be the undesirable result of a long delay between polishing and etching and/or an improper chemical composition of the etchant. The time between polishing and etching should be minimized (about $10 \mathrm{~s}$ ) to have the minimum influence of the oxide formation on the surface of the polished sample. Overetching by Beraha, as shown in Fig. 6b, can also adversely affect the contrast between ferrite and austenite, where ferrite shows some broken etched layers and austenite has a heterogeneous contrast.

To sum up, the best etchant was found to be modified Beraha; however, a proper etching procedure must be followed to produce high-quality micrographs especially for IA. The modified Beraha etchant is therefore used to compare PC and IA with EBSD in the next section.

\subsubsection{Ferrite measurement technique}

Table 3 details the ferrite fraction on the weld centerline of the reference sample measured using IA, PC, and EBSD. The average reported for IA was measured by considering the measurement of 6 fields on the weld centerline by each company. More details about each measurement are present in the next section. In addition to modified Beraha, SMT also measured ferrite fraction using PC on the reference sample electrolytically etched using $10 \% \mathrm{KOH}$.

The IA technique and EBSD showed a difference of only $0.4 \%$, while the standard deviations of ferrite fractions measured using IA and EBSD were $2.6 \%$ and $2.3 \%$, respectively. The EBSD results are expected to be more accurate as an indexing rate of $98 \%$ was achieved for the reference sample. It clearly illustrated that IA produced a very accurate ferrite fraction measurement, where its standard deviation and average value are almost similar to those for the reference EBSD technique. The comparison of PC with IA and EBSD indicates
Fig. 6 Improper etching using modified Beraha. a Low contrast between fine ferrite and austenite and $\mathbf{b}$ formation of crack-like features in the colored area in ferrite and bright areas in austenite. From a GMAW welded L-joint

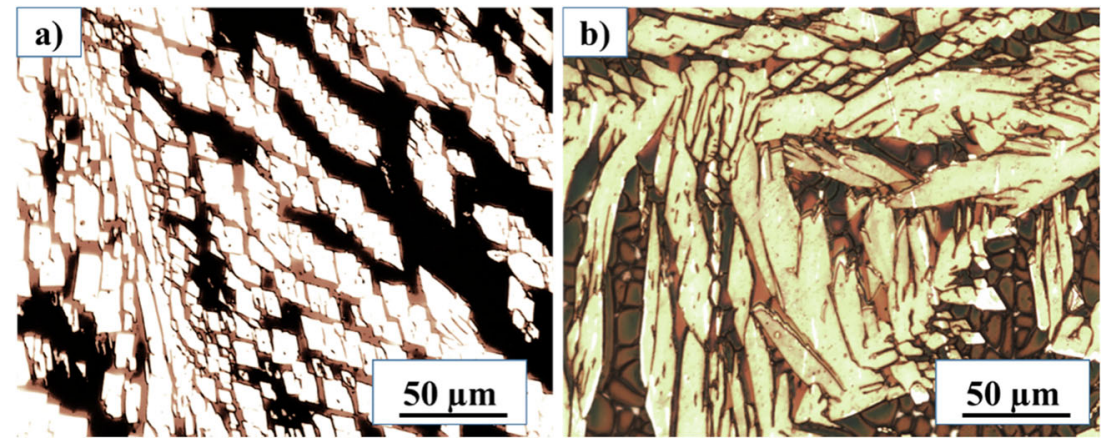


Table 3 Ferrite fraction measured using different techniques

\begin{tabular}{llll}
\hline Method & Average & Range & Standard deviation \\
\hline IA (\%)* & 68.0 & - & 2.6 \\
PC-ASTM E562-10\% KOH (\%) & - & $60.5-61.8$ & - \\
PC-ASTM E562-Beraha (\%) & - & $59.8-63.2$ & - \\
EBSD (\%) & 67.6 & - & 2.3 \\
\hline
\end{tabular}

*Average of all data points of partners in the first 6 images from the weld zone. For Outokumpu, the results for the Olympus microscope was used that the PC underestimated ferrite fraction, which is more pronounced for $10 \% \mathrm{KOH}$. Thus, the PC technique not only takes much longer time than IA but also has a lower accuracy. Therefore, IA of the reference sample etched with modified Beraha was selected as the best technique to perform a Round Robin test, which will be discussed in the next section.

\subsubsection{Round Robin test}

As described, the Round Robin test was performed on the reference sample etched with Beraha at different partners' laboratories. The microstructure of the sample at the top, middle, and bottom of the weld zone is shown in Fig. 7. As may be seen, the distribution of ferrite is uniform and only a few fine ferritic regions between austenite grains may be found. The sample, therefore, is suitable for a Round Robin test, as it has a microstructure with a suitable distribution of ferrite and proper ferrite to austenite contrast in all regions.

The ferrite fraction of the reference sample on the weld centerline measured in the different laboratories is shown in Fig. 8. The locations where micrographs were taken are shown in Fig. 2. The trend of ferrite fraction variation from the weld zone to the base metal is similar in all laboratories. SMT measured the highest and OS the lowest ferrite fractions in general. Based on Fig. 2, the first eight micrographs taken by each laboratory were judged to be from the weld zone. However, to minimize the risk of measuring the ferrite fraction in the HAZ, only the first six micrographs from each laboratory were used. The ferrite fractions of the weld zone were within the same range and no unexpected fractions were recorded.

As explained in the experiment, OS measured ferrite fraction on the etched sample (without re-etching) using different microscopes. As OS received the reference sample from SMT in the etched condition, the ferrite fraction measured by SMT and OS with the different microscopes are illustrated in Fig. 9. Comparison of Fig. 8 and Fig. 9 reveals that the variation between laboratories with re-polishing and re-etching the sample can have a similar effect as changing the microscopes without altering other variables. The combinations of different microscopes and cameras, as well as a slight change in the location of the micrographs, are likely explanations for scatter in results obtained with different microscopes.

The average ferrite fractions of the weld zone measured by the partners are detailed in Table 4. As may be seen, the average ferrite fraction measured by different partners and different microscopes is within the range between $65.8 \pm 2.4 \%$ and $70.7 \pm 3.1 \%$. Including the standard deviation for the maximum and minimum ferrite fractions, they show an overlap at $67.6-68.2 \%$, which is exactly within the range that was measured by EBSD. It, therefore, shows that ferrite fraction measurements are repeatable in different laboratories and using different microscopes.

As detailed in Fig. 9 and Table 4, the SMT values are higher than those for other participants. The reason is not

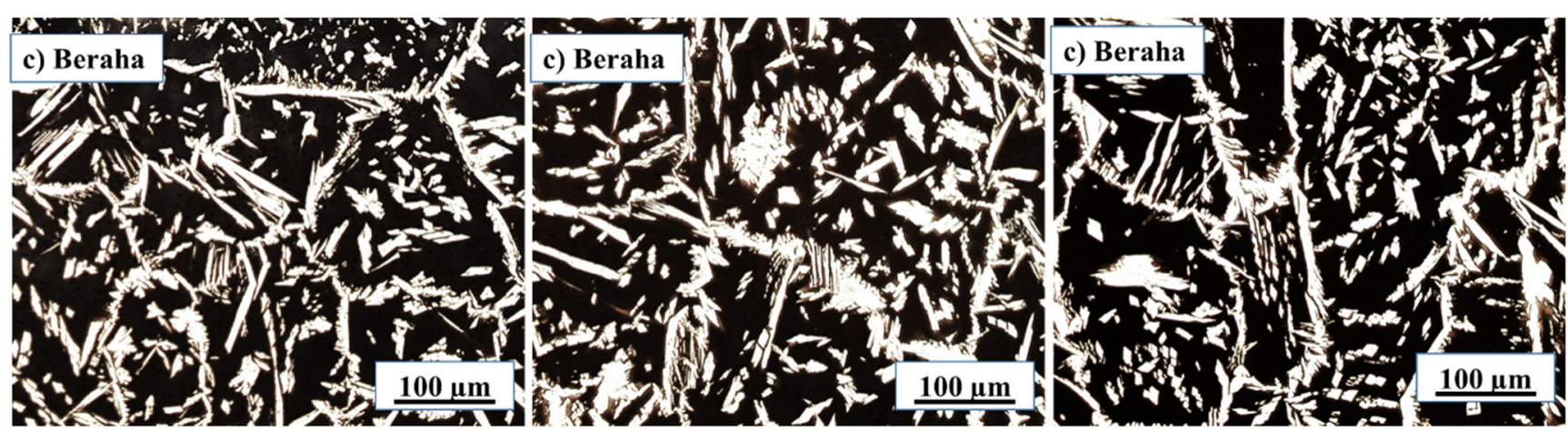

Fig. 7 Microstructure of the top, middle, and bottom of the 6-mm GTAW reference sample cross section etched with modified Beraha showing a uniform distribution of ferrite and austenite with high contrast 
Fig. 8 The ferrite fraction in the 6-mm-thick GTAW remelted sample measured by different partners. By considering Fig. 2 and micrographs, it was decided to use the first six images for comparison as they are more probable to be located at the same position
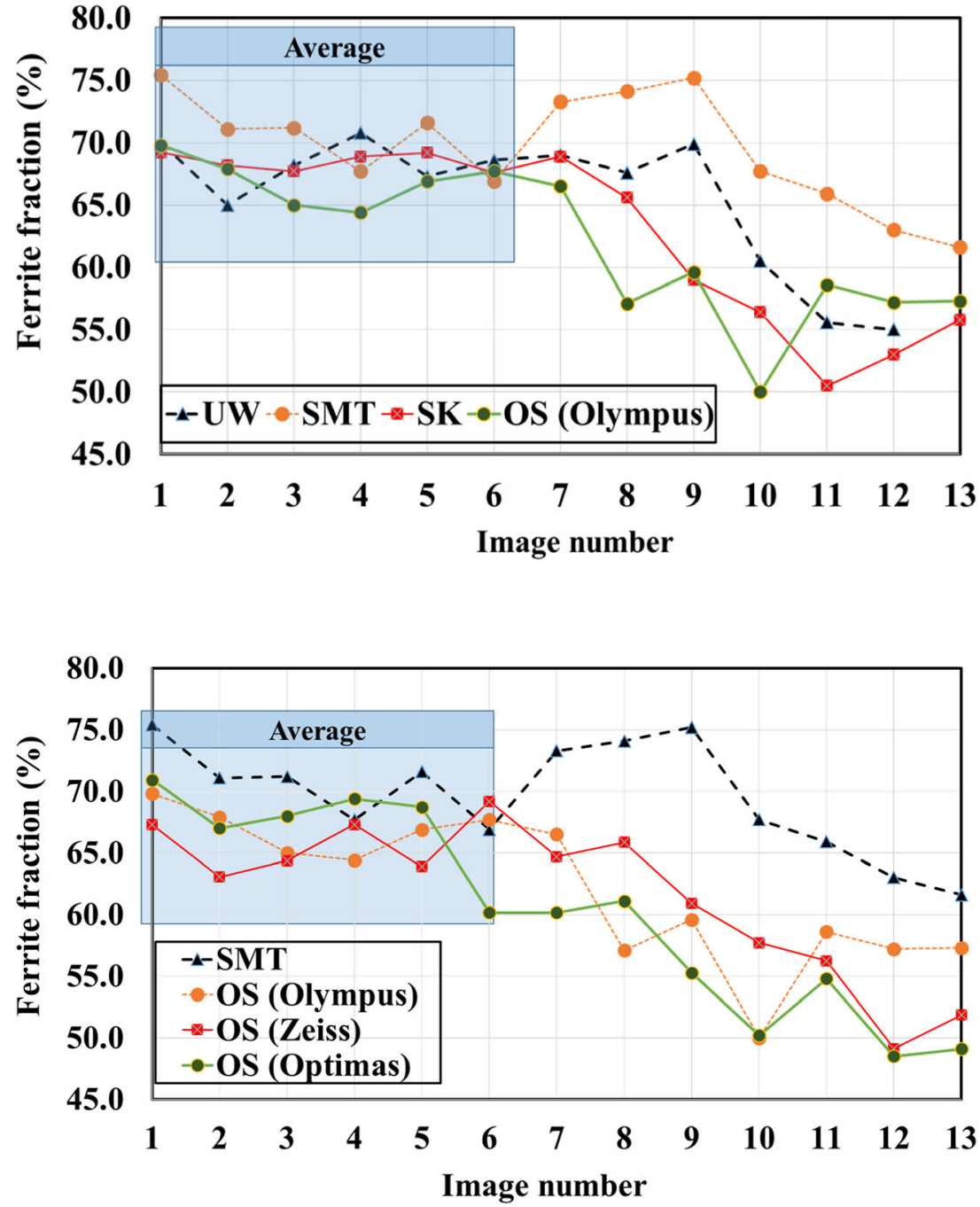

Fig. 9 The ferrite fraction in the cross section of the reference sample (6 mm GTAW remelted) measured with different microscopes in Outokumpu and Sandvik for the same etched sample clear, but a possible explanation could be the setting of the threshold in the IA software.

To conclude the Round Robin results, ferrite fraction measurements performed at different laboratories showed a very small variation, which was in the range of changing the microscopes in the same laboratory. The results were very reproducible and accurate. Therefore, the IA technique on modified Beraha etched samples is suitable for measuring ferrite fraction in SDSS singlepass welds.

\subsection{Ferrite fraction and ferrite number for single-pass welds}

The next step was to measure the ferrite fraction for the 14 single-pass welds produced with different welding

Table 4 The average ferrite fraction of weld zone for each partner

\begin{tabular}{lllll}
\hline Lab & Microscope & Ferrite fraction (\%) & Standard deviation (\%) & 95\% interval (\%) \\
\hline University West & Olympus & 68.3 & 2.1 & 2.1 \\
Swerea KIMAB & Leica IM DRM & 68.5 & 0.7 & 0.8 \\
Sandvik Materials Technology & Reichert MEF4M & 70.7 & 3.1 & 3.2 \\
Outokumpu Stainless AB & Olympus & 67.0 & 2.0 & 2.1 \\
& Zeiss & 65.8 & 3.8 & 2.5 \\
& Optimas & 67.4 & & 4.0 \\
\hline
\end{tabular}


Fig. 10 The relationships between average ferrite fraction and ferrite number for the 14 single-pass welds: a the cross section of weld metal and $\mathbf{b}$ the top of the cross section and surface of the welds a)
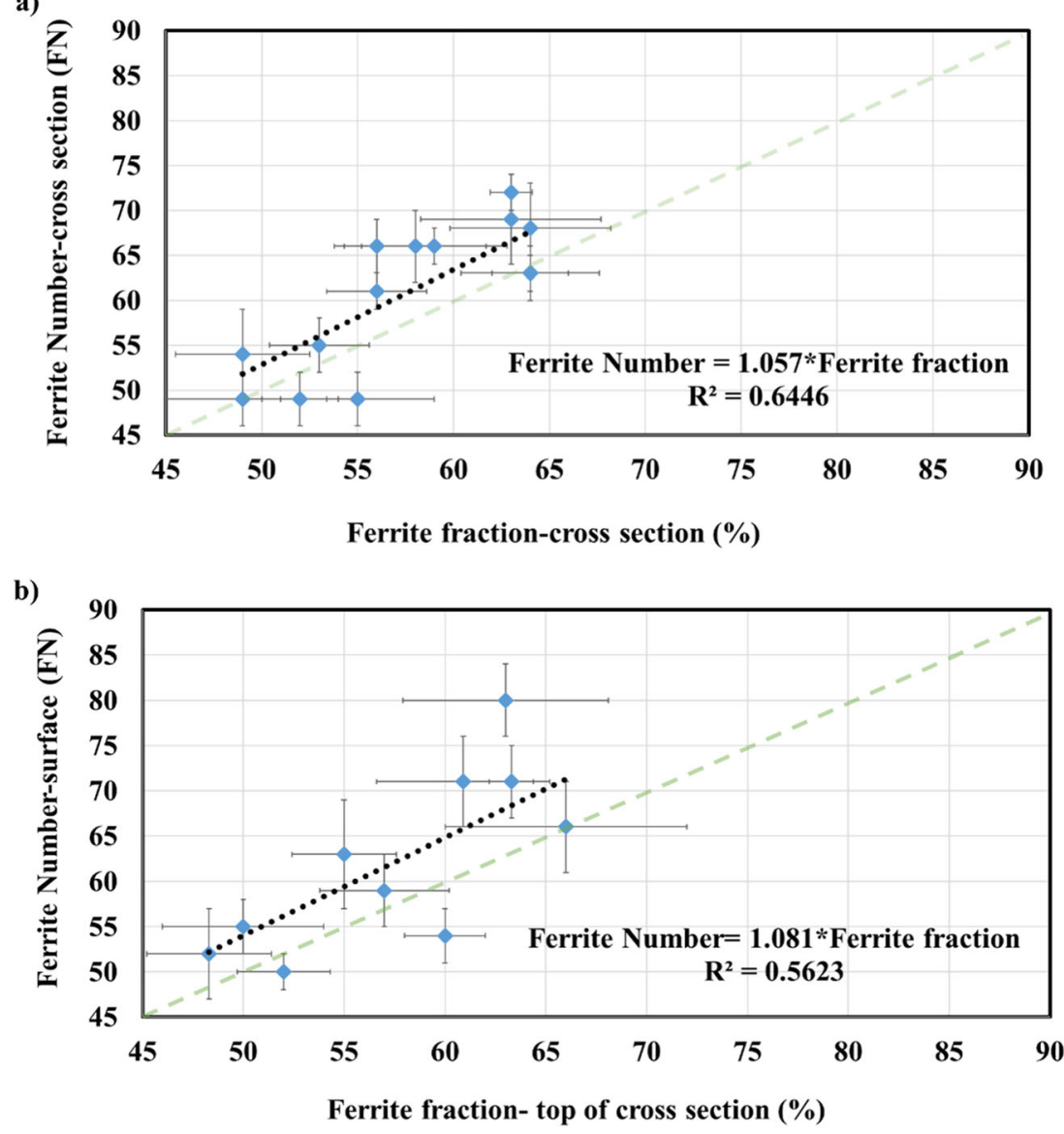

parameters and to find the relationship between ferrite fraction and ferrite number. The locations used for ferrite fraction and number measurements in each weld are shown in Fig. 2. To find the relationship between the ferrite fraction and number, the measurements on the cross section of the welds are expected to give the best correlation. Therefore, the ferrite number measurements were performed exactly on the same locations where the ferrite fractions were measured.

The relationship between ferrite fraction and number in the cross section of the weld zones is shown in Fig. 10a. A formula was extracted by linear regression between numbers and fractions valid for the ferrite fraction range of $45-65 \%$ as follows:

Ferrite Number $(\mathrm{FN})=1.057 \times$ Ferrite fraction $(\%)$

The other possible and more practical approach is to find the relationship between Ferrite Number and ferrite fraction at the surface of the weld zones. In this approach, the ferrite fractions were measured on the top of cross section (about $0.2 \mathrm{~mm}$ from the surface as shown in Fig. 2 ) and the ferrite numbers were measured along the centerline of the weld surface (Fig. 2). The ferrite fractions and numbers determined using this approach are shown in

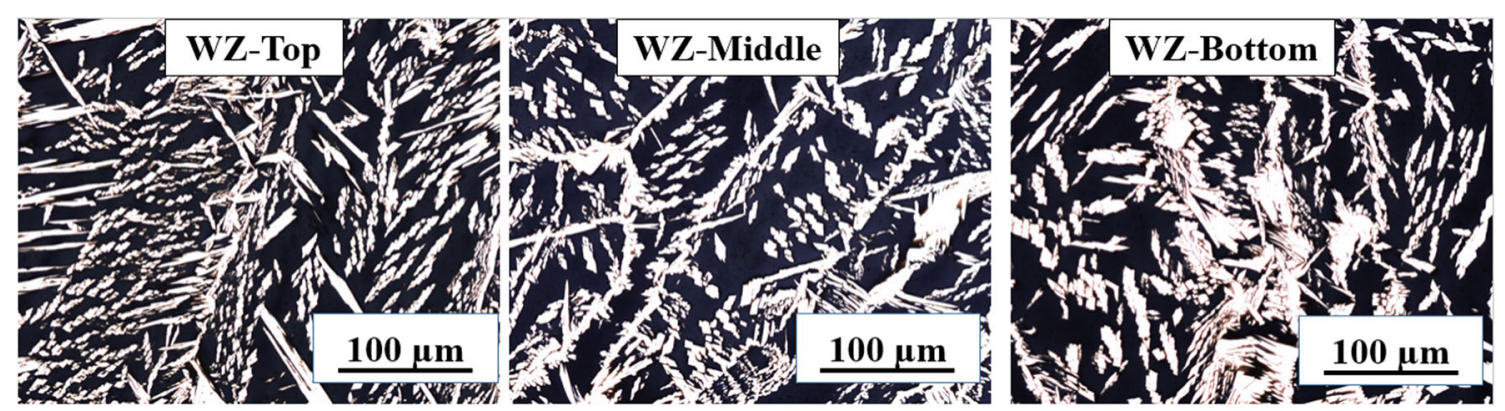

Fig. 11 Microstructure at the top, middle, and bottom of V-grooved sample welded with SMAW with 2509 electrode 
Fig. 12 a Relationship between ferrite fraction at the top of the cross section and average ferrite fraction in the entire cross section of 14 single-pass welds. b Relationship between ferrite number on the weld surface and cross sections of welds
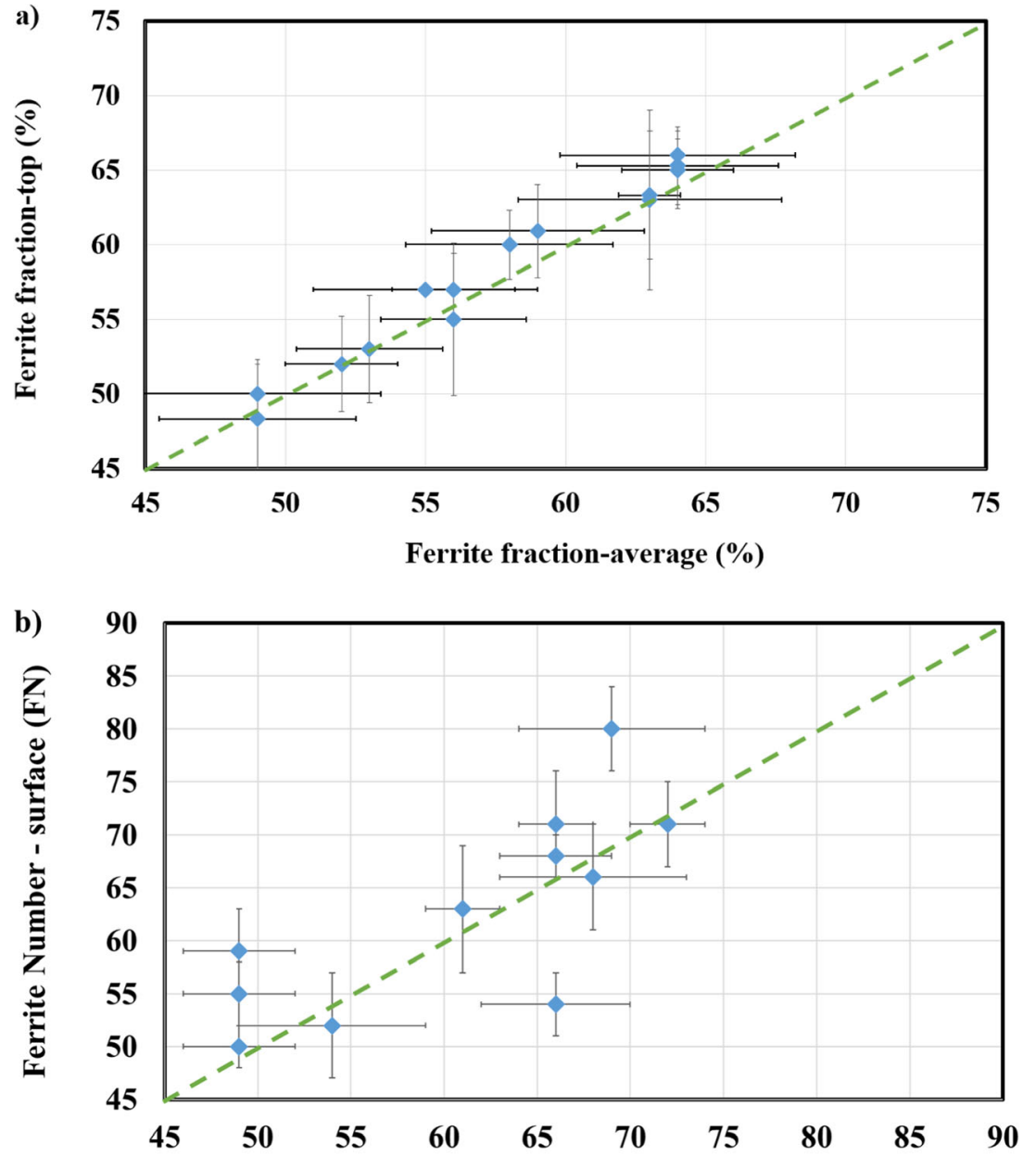

Ferrite Number - cross section (FN)
Fig. 10b. The linear equation relationship between numbers and fractions is as follows:
Ferrite Number $(\mathrm{FN})=1.081 \times$ Ferrite fraction $(\%)$
Table 5 Details about ferrite number and ferrite fraction of 14 single-pass welds

\begin{tabular}{lllll}
\hline Joint & FP $\%$ & FN & FP\% \\
& Cross section & Cross section & Top of cross section & $\begin{array}{l}\text { FN } \\
\text { Top surface }\end{array}$ \\
\hline Corner - 13 mm GMAW low HI & $55 \pm 4$ & $49 \pm 3$ & $57 \pm 3$ & $59 \pm 4$ \\
Corner - 13 mm GMAW high HI & $52 \pm 2$ & $49 \pm 3$ & $52 \pm 2$ & $50 \pm 2$ \\
Corner - 13 mm SAW & $56 \pm 2$ & $66 \pm 3$ & $57 \pm 2$ & $68 \pm 2$ \\
T-13 mm GMAW low HI & $58 \pm 4$ & $66 \pm 4$ & $60 \pm 2$ & $54 \pm 3$ \\
T-13 mm GMAW high HI & $49 \pm 4$ & $49 \pm 3$ & $50 \pm 4$ & $55 \pm 3$ \\
V-grooved 13 mm plate GMAW & $49 \pm 3$ & $54 \pm 5$ & $48 \pm 3$ & $52 \pm 5$ \\
V-grooved 13 mm GTAW & $59 \pm 4$ & $66 \pm 2$ & $61 \pm 4$ & $71 \pm 5$ \\
V-grooved 13 mm SAW & $63 \pm 1$ & $72 \pm 2$ & $63 \pm 1$ & $61 \pm 4$ \\
V-grooved 13 mm SMAW & $64 \pm 4$ & $68 \pm 5$ & $66 \pm 6$ & $80 \pm 4$ \\
Butt 3 mm GTAW & $63 \pm 5$ & $69 \pm 5$ & $63 \pm 5$ & $63 \pm 6$ \\
V-grooved 10 mm GTAW & $56 \pm 3$ & $61 \pm 2$ & $55 \pm 2$ & - \\
V-grooved 21 mm GTAW & $64 \pm 4$ & $63 \pm 2$ & $65 \pm 3$ & - \\
V-grooved 21 mm GTAW & $53 \pm 3$ & $55 \pm 3$ & $53 \pm 3$ & - \\
Double V 25 mm GTAW & $64 \pm 2$ & $63 \pm 3$ & $65 \pm 2$ & \\
\hline
\end{tabular}




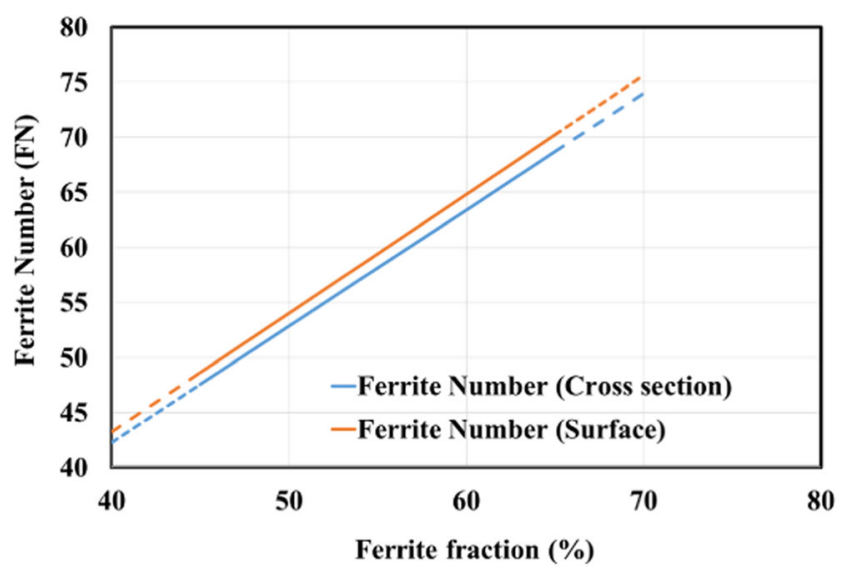

Fig. 13 Prediction of ferrite number-ferrite fraction relationship on the cross section and weld surface using Eqs. 1 and 2 (14 welds). The broken lines are the extrapolation for higher and lower fractions, which were not evaluated in this study

Comparison of Fig. 10a and b shows that the results obtained for the top and surface are more scattered compared to those for the cross section. Therefore, it is needed to find a correlation between average ferrite fractions on the entire cross section (determined from minimum 21 pictures from the top, middle, and bottom of each weld) and on the top as well as between ferrite number on the cross section and the weld top surface. As a result, it will be possible to find the origin of the increased deviation in Fig. 10b.

The typical microstructure for the top, middle, and bottom locations in a single-pass weld (for SMAW) is shown in Fig. 11. As may be seen, the distribution of ferrite at the top of the cross section (Fig. 2) is quite similar to the distribution in the middle and bottom. The relationship between the ferrite fraction at the top and average values for each 14 in weld is presented in Fig. 12a (Table 5). The diagram shows how these two values are in good agreement and proves that ferrite fraction at the top is a good representative of the average ferrite fraction, as visually shown in Fig. 11.
The relationship between the ferrite numbers of the cross section and surface is illustrated in Fig. 12b. As may be seen, the deviation is much higher than that for the ferrite fraction; however, they illustrate a reasonable agreement. Some possible reasons for the deviation could be different curvatures on the surface of welds, measurement of weld metal and HAZ together, and heterogeneous ferrite content along the weld seams, as well as different microstructural texturing through $\mathrm{x}-$ and $\mathrm{z}-$ directions.

To compare the ferrite fraction-number equations obtained for the SDSS welds on the cross section and the surface, Fig. 13 is drawn using Eqs. 1 and 2. As may be seen, both equations predicated very similar ferrite numbers. It could be concluded that the ferrite number measurement on the ground surface of single-pass weld is an acceptable representative of ferrite fraction on the top of the cross section as well as the entire cross section of a weld zone.

\subsection{Final comments}

The present study clearly showed that using the modified Beraha reagent for etching followed by image analysis is a reproducible, reliable, and accurate technique to measure ferrite fraction. This approach is in agreement with studies performed by Jonsson et al. [16], Varbai et al. [17], and Putz et al. [22], where all suggested etching followed by IA can be used to accurately measure the ferrite fraction. A suitable etching practice will minimize the required post-processing of the micrographs, otherwise a more advanced software with adjustable settings is needed to measure the ferrite fraction.

The correlation of ferrite fraction and ferrite number (Eqs. 1 and 2) can be rounded and represented with the following equation in super duplex stainless steel single-pass welds:

Ferrite Number $(\mathrm{FN})=1.1 \times$ Ferrite fraction $(\%)$
Fig. 14 The relationship between ferrite fraction and number for the present study and from literature. The orange-shaded area is the expected relation suggested in the Fischer FERITSCOPE® manual [24]

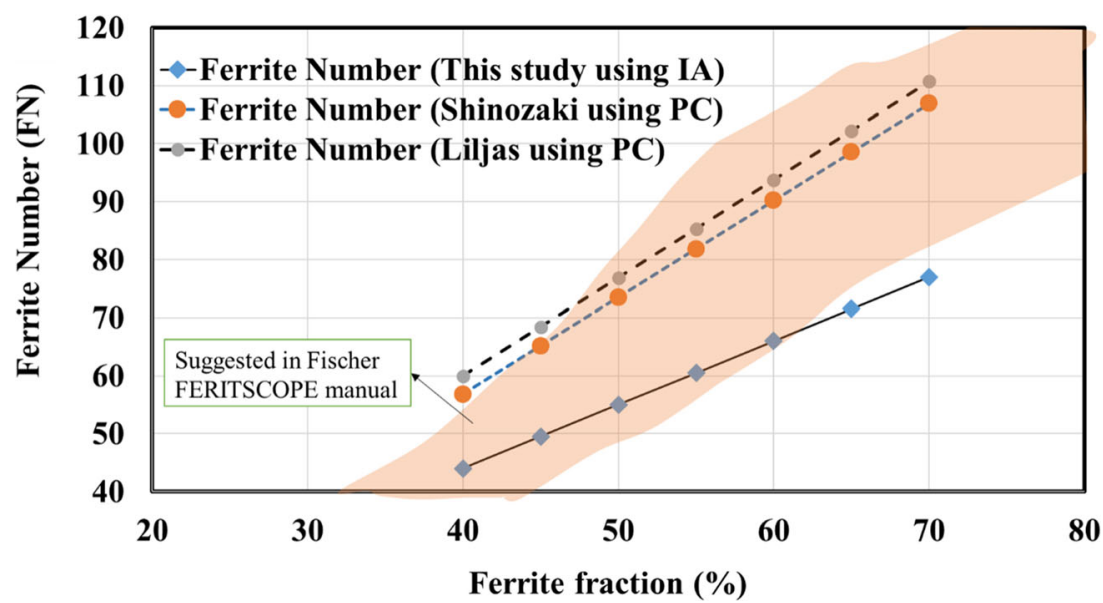


The maximum scatter of ferrite numbers recorded from this equation was $+10 \mathrm{FN}$ and $-5 \mathrm{FN}$ for the weld surface and +6 $\mathrm{FN}$ and $-10 \mathrm{FN}$ for cross sections.

A comparison of this equation with those reported in the literature is shown in Fig. 14. This study predicted lower ferrite fractions compared to Shinozaki et al. [25] and Liljas et al. [26]. However, a comparison with the diagram presented by Fischer [24] shows that the results mostly fall within the suggested correlation area. It should be noted that the difference between this study and the literature could be the result of several factors. The chemical composition of SDSS welds has about $6 \%$ less iron content than DSS welds produced by 2209 type filler metal, which could explain the difference when comparing with the formula reported by Liljas [26]. In addition, it was shown that image analysis is more accurate than to PC used for this study, where PC underestimated the ferrite fraction with about $8 \%$. Therefore, the formula determined using IA is expected to be different from those in the literature, as different measurement techniques were used.

It should be noted that Eq. 3 and Fig. 14 are based on results for single-pass arc welds with ferrite fractions in the range of 40-70\%. Further studies would be needed to verify the validity of the formula for other welding processes and ferrite fractions.

\section{Conclusions}

Comprehensive ferrite measurement experiments were performed on super duplex stainless steel welds. Different etching procedures and ferrite measurement techniques were used. The conclusions are as follows:

1. The ranking of etching procedures giving maximum to minimum contrasts between ferrite and austenite is as follows: modified Beraha color etching, 20\% NaOH electrolytic etching, two-step electrolytic etching using $10 \% \mathrm{NaOH}$ and $7 \%$ oxalic acid, and $10 \%$ oxalic acid electrolytic etching.

2. Image analysis showed a similar ferrite fraction $(68.0 \pm$ $2.6 \%)$ as that measured by EBSD $(67.6 \pm 2.3 \%)$ on a sample etched with a modified Beraha etchant for a reference type 2507 SDSS weld sample. Point counting, however, underestimated ferrite fraction by $8 \%$.

3. A Round Robin test was performed by University West, Swerea KIMAB, Sandvik Materials Technology, and Outokumpu Stainless AB. A sample was etched using the same practice, and ferrite fraction was measured in similar locations. Results showed that the average ferrite fractions were within the range of $68.3 \% \pm 2.1$ to $70.7 \pm 3.1$.
4. The maximum difference between the average ferrite fractions measured using three different microscopes was only $1.6 \%$, while the maximum standard deviation was $3.8 \%$. It means that changing the microscope did not influence the results significantly.

5. Ferrite fractions and numbers were measured in 12 different single-pass welds produced by different welding processes, heat inputs, and joint geometries. Results showed that the relationship between ferrite fraction and ferrite number in the welds was Ferrite Number $(\mathrm{FN})=1.1 \times$ Ferrite fraction $(\%)$ for ferrite fractions between 45 and $65 \%$.

6. Image analysis of the 14 single-pass welds showed that the weld zone ferrite distribution was very homogenous and the average ferrite fraction in the entire cross section is representative of the average close to the top side of the cross section ( $0.2 \mathrm{~mm}$ from the surface). The ferrite numbers measured on the cross section and on the weld surface showed an acceptable correlation too.

Acknowledgments The great support received from the DuWelTool project partners (ELGA AB, Svetskommissionen, Jernkontoret, ThermoCalc Software AB, Voestalpine Böhler Welding Nordic AB, and Forsmarks Kraftgrupp AB) is acknowledged. Authors also would like to thank Dr. Raveendra Siriki from Sandvik Materials Technology for performing EBSD phase fraction measurements.

Funding information Financial support from Vinnova Foundation for the DuWelTool project (project number 2016-02834) is appreciatively acknowledged. The financial support from the KK Foundation for the research school SiCoMaP (20140130) is acknowledged.

Open Access This article is distributed under the terms of the Creative Commons Attribution 4.0 International License (http:// creativecommons.org/licenses/by/4.0/), which permits unrestricted use, distribution, and reproduction in any medium, provided you give appropriate credit to the original author(s) and the source, provide a link to the Creative Commons license, and indicate if changes were made.

\section{References}

1. Karlsson L (2012) Welding of duplex stainless steels - a review of current recommendations. Weld World 56(5):6

2. Nilsson J-O, Chai G (2010) The physical metallurgy of duplex stainless steels. Paper presented at the Duplex Stainless Steel Conference, Beaune,

3. A Hosseini V, Karlsson L, Engelberg D, Wessman S (2018) Timetemperature-precipitation and property diagrams for super duplex stainless steel weld metals. Weld World 62(3):517-533

4. Hosseini V, Hurtig K, Karlsson L (2017) Effect of multipass TIG welding on the corrosion resistance and microstructure of a super duplex stainless steel. Mater Corros 68(4):405-415

5. Hosseini VA, Wessman S, Hurtig K, Karlsson L (2016) Nitrogen loss and effects on microstructure in multipass TIG welding of a super duplex stainless steel. Mater Des 98:88-97

6. Hosseini VA, Bermejo MAV, Gårdstam J, Hurtig K, Karlsson L (2016) Influence of multiple thermal cycles on microstructure of 
heat-affected zone in TIG-welded super duplex stainless steel. Weld World 60(2):233-245

7. Messer B, Oprea V, Wright A (2007) Duplex stainless steel welding: best practices. Stainl Steel World 53-63

8. API Technical Report 938-C: Use of duplex stainless steels in the oil refining industry (2011). Second edn. API

9. NACE (2015) ANSI/NACE MR0175/ISO 15156: petroleum, petrochemical, and natural gas industries - materials for use in H2Scontaining environments in oil and gas production general principles for selection of cracking-resistant materials. Houston, Texas

10. Nanavati PK, Kotecki DJ, Soman SN (2018) Effect of ferrite content on mechanical properties and stress corrosion cracking resistance in $22 \mathrm{Cr} 5 \mathrm{Ni}$ duplex stainless steels welded joints. Paper presented at the IIW Intermediate Meeting Genoa

11. Hosseini VA, Karlsson L, Wessman S, Delic A, Wahlsten J (2018) Creating a database for software predicting duplex stainless steel weld microstructures. Paper presented at the IIW Intermediate Meeting, CIX-H, Genoa

12. Farrar J (2005) The measurement of ferrite number (FN) in real weldments. Weld World 49(5-6):13-21

13. Forgas Júnior A, Otubo J, Magnabosco R (2016) Ferrite quantification methodologies for duplex stainless steel. J Aerosp Technol Manag 8(3):357-362

14. Kotecki D (1997) Ferrite determination in stainless steel weldsadvances since 1974. Weld J, 76 (1):24-s to 37-s

15. Bermejo (2012). Predictive and measurement methods for delta ferrite determination in stainless steels. Weld J, 91(4):113-s to 121-s
16. Jonsson J, Runnsjö G, Pettersson R (2010) Quantitative evaluation of phase fractions in duplex stainless steels. Paper presented at the Duplex Stainless Steel, Beaune

17. Varbai B, Pickle T, Májlinger K (2017) Development and comparison of quantitative phase analysis for duplex stainless steel weld. Period Polytech Mech Eng 62(3):247-253

18. Vol AH (2004) 9: Metallography and microstructures. ASM International, Materials Park, $\mathrm{OH}$

19. Lefebvre J (1993) Guidance on specifications of ferrite in stainless steel weld metal. Weld World 31(6):390-407

20. Niagaj J, Mazur $€$ (2014) Review of methods for measurement of ferrite content in high alloyed steels and their welded joints. Weld Int 28(5):345-353

21. Bermejo MAV, Eyzop D, Karlsson L, Svensson L-E, Hurtig K (2017) Influence of multi-pass welding on the microstructure and properties of superduplex stainless steels (IIW Doc IX-2607-17). Paper presented at the IIW Annual Assembly, China

22. Putz A, Althuber M, Zelić A, Westin EM, Willidal T, Enzinger N (2018) Optimized method for measurement of ferrite content in multi-pass duplex stainless steel welds (IX-8644-18). Paper presented at the IIW Intermediate meeting-C IX-H, Bali

23. International A ( 2015) ASTM A262-15: standard practices for detecting susceptibility to intergranular attack in austenitic stainless steels. West Conshohocken, PA

24. Operating Manual FERITSCOPE® MP30 (2010)

25. Shinozaki K, Ke L, North T (1992) Hydrogen cracking in duplex stainless steel weld metal. Weld J 71:387-s

26. Liljas M, Qvarfort R (1986) Influence of nitrogen on weldments in UNS S 31803. Acom 1(2):2-12 